\title{
On the Development of a Harmonized, User-Centered Terminology for Current and Upcoming ICT Devices, Services and Applications
}

\author{
Bruno von Niman ${ }^{1,4()}$, Martin Böcker ${ }^{2,4}$, and Angel Boveda ${ }^{3,4}$ \\ ${ }^{1}$ Vonniman Consulting, Dalen 13, 13245 Saltsjö-Boo, Sweden \\ bruno@vonniman. com \\ ${ }^{2}$ Dr. Böcker \& Dr. Schneider GbR, Constance, Germany \\ boecker@humanfactors. de \\ 3 Wireless Partners SLL, Sangenjo 5, 28034 Madrid, Spain \\ angel . boveda@wirelesspartners.es \\ ${ }^{4}$ ETSI TC Human Factors Specialist Task Force 540, Sophia Antipolis, France
}

\begin{abstract}
Unfamiliar terms used in the user interface (UI) of an Information and Communication Technology (ICT) device, service or application may present an obstacle to users, if unfamiliar with them or uncertain about their technical meaning and intended functionality. The availability of a harmonised, usercentred terminology benefits users with functional variations, such as those with literacy difficulties, or people with varying visual needs or cognitive capabilities. This paper presents on-going standardization work, focusing on improving the overall usability and accessibility through the development of recommendations addressing terminology harmonization among devices, services and applications to a well-defined degree, in areas not intended to convey a certain brand-specific feature or image.
\end{abstract}

Keywords: Harmonization - Terminology · User-centered

\section{Background}

Unfamiliar terms used in the UI of an ICT device, service or application may present an obstacle to users, if uncertain about their technical meaning or intended functionality. Furthermore, terms may be introduced by manufacturers to denote new features, or to distinguish own features from those offered by competitors. Most technical terms are not intended for brand-related positioning or differentiation. In the absence of a common terminology for the most frequently used and common elements, the use of terms differs considerably among manufacturers and service providers.

This paper presents an alternative, with focus on improving the overall user experience and accessibility through the development of recommendations addressing terminology harmonization (to a well-defined degree) among devices, services and applications. 
A common terminology can be employed to help prevent negative effects such as increased user difficulties in understanding and accessing complex, ambiguous and inconstantly-used terms leading to unnecessary confusion, increased efforts in user education and costs for user support, limited feature discovery, unclear user expectations and a limited uptake in use (as users may be reluctant to use fuzzy features) [2], or even increased cognitive complexity and subsequent learning efforts.

The need for harmonization increases as new features and services are being introduced at an increased pace in the world of agile ICT development and as new device and service providers continue to enter today's dynamic market.

In addition, as network operators' business models develops, end-user loyalty may decrease. The introduction of new features without the timely and instant availability of accessible user documentation impacts on the usability and accessibility of ICT.

\section{Approach and Addressed Users}

While terms may be introduced by manufacturers to denote new features, or to distinguish own features from those offered by competitors, most technical terms are not intended for brand-related differentiation. In the absence of a common terminology for the most frequently used and common elements, the use of terms differs considerably among manufacturers and service providers.

This paper describes an alternative, focusing on improving the overall user experience through the development of recommendations addressing terminology harmonization (to a well-defined degree) among devices, services and applications (in areas not intended to convey a certain brand-specific feature or image).

A common terminology can be employed to help prevent negative effects such as increased user difficulties in understanding complex, ambiguous and inconstantly-used terms leading to unnecessary confusion, increased efforts in user education and costs for user support, limited feature discovery, unclear user expectations and a limited uptake in use (as users may be reluctant to use fuzzy features), or even increased cognitive complexity and subsequent learning efforts.

The need for harmonization increases as new features and services are being introduced continuously, at an increased speed in the world of agile ICT development and as new device and service providers continue to enter today's dynamic market.

In addition, as network operators' business models change, end-user loyalty to network operators and device manufacturers may decrease. The introduction of new features without the timely and easy availability of user documentation is another factor with a considerable impact on the usability and accessibility of ICT.

Intended readers of the ETSI Guide under development will include device manufacturers, application developers, service providers, network operators, technical writers and developers of marketing materials, national and international standards bodies and regulatory institutions.

Its intended users are those designing, developing, implementing and deploying user interfaces for and interaction with ICT devices, services, and applications. 
All users are expected to benefit from this work, including young and older people and specifically, people with functional limitations (e.g. within the cognition area [3]).

\section{Method and Collaborative Processes}

The development work reported will be conducted in a close collaboration with experts representing the ICT industry and interested and relevant stakeholders and will be based upon a combination of desk research, expert knowledge and an industry-wide collaboration, consultation, review and consensus process, in three main phases:

1. Identification of objects and activities to be addressed;

2. Collection of terms used by major providers; and

3. Analysis, selection and presentation of the recommended terms.

The most common functional areas (see clause 3 below) will be identified, grouped and selected to be covered by the work.

For each functional area, relevant and representative providers will be selected and the terms used by them for the most frequently used, specific objects and activities of the respective functional areas will be collected in the five languages (English, French, German, Italian and Spanish) covered by the reported work.

In the final phase of the work, the collected terms will be reviewed and the recommended terms will be selected, based on a variety of checks (e.g. for consistency between manufacturers (i.e. prevalence of certain terms)) and described and presented with focus on practical use, as reported in detail in [1].

During this process, a Reference group consisting of domain experts will be established and used to discuss, review and validate the selections and assist in the harmonization effort. Experts interested to contribute are invited to visit our homepage for additional details and the latest draft and contact us to identify the optimal forms of collaboration.

\section{Results}

The result will consist of a detailed list of terms listed in the Guide, providing principles of use and deployment and the terms themselves, grouped and presented by the five language-specific versions of the basic commands. At the moment of the writing of this paper, the following functional groups are intended to be covered:

1. Basic and interaction-related terms;

2. Non-functional, interaction-related terms (that also covers the most common accessibility and assistive device connectivity-related terms);

3. Telephony services;

4. Media handling;

5. Messaging;

6. Navigation and maps;

7. Banking and payments; 
8. eHealth services;

9. Travel services;

10. Searching and browsing;

11. Social media;

12. Photography and imaging;

13. Games and tools; and

14. Miscellaneous (as, and if necessary).

Due to space limitations, further details are not provided here but interested readers are invited to visit our homepage and download the latest draft, or contact the authors directly during the development phase.

The final result will have to be approved by the ETSI Human Factors Committee (TC HF), as well as the representatives of the ETSI Membership community, consisting of some 800 member organizations, non-exhaustively including user representatives, standards bodies, startups, research entities, SMEs developing, deploying or using ICT, accessibility, user and disability associations, network operators, policy makers and most of the largest ICT corporations.

\section{Conclusions, Recommendations and Future Steps}

The aim of our work is a quick uptake and the widest possible support in product implementations in the widest possible range - eased by the easy and free, on-line availability of the publication and its unrestricted use.

We intend to openly report about our experiences, in order to ease and optimize possible future updates and expansions.

Future expansion possibilities envisaged include updated vocabularies and expanded language coverage (e.g. to the official EU/EFTA ones, or minority languages used in Europe).

Acknowledgements. This work, performed during 2017-2019, is co-funded by the European Telecommunications Standards Institute (ETSI), the European Commission (EC) of the European Union (EU) and the European Free Trade Association (EFTA).

\section{References}

1. ETSI DEG 203 499: Human Factors (HF); User-centered terminology for existing and upcoming ICT devices, services and applications. Draft under development, for publication in July 2019. This is the topic of this paper!

2. ETSI EG 202132 v1.1.1 (2004-08): Human Factors (HF); User Interfaces; Guidelines for generic user interface elements for mobile terminals and services. www.etsi.org

3. ETSI EG 203350 v1.1.1 (2016-11): Human Factors (HF); Guidelines for the design of mobile ICT devices and their related applications for people with cognitive disabilities 
Open Access This chapter is licensed under the terms of the Creative Commons Attribution 4.0 International License (http://creativecommons.org/licenses/by/4.0/), which permits use, sharing, adaptation, distribution and reproduction in any medium or format, as long as you give appropriate credit to the original author(s) and the source, provide a link to the Creative Commons license and indicate if changes were made.

The images or other third party material in this chapter are included in the chapter's Creative Commons license, unless indicated otherwise in a credit line to the material. If material is not included in the chapter's Creative Commons license and your intended use is not permitted by statutory regulation or exceeds the permitted use, you will need to obtain permission directly from the copyright holder.

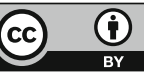

